\title{
Results of the use of Kahoot! gamification tool in a course of Chemistry
}

\author{
Ares, Ana María ; Bernal, Jorge ${ }^{\text {; }}$ Nozal, María Jesús ${ }^{a}$; Sánchez, Francisco Javier \\ and Bernal, Joséa \\ ${ }^{\mathrm{a} D e p a r t m e n t}$ of Analytical Chemistry, Universidad de Valladolid, Spain, ${ }^{\mathrm{b}}$ Computer \\ Science Department and Computer Vision Center, Universitat Autònoma de Barcelona, \\ Spain
}

\begin{abstract}
The present study examines the use of Kahoot! as a gamification tool to explore mixed learning strategies. We analyze its use in two different groups of a third-year theoretical subject in the Degree in Chemistry. An empiricalanalytical methodology was used among two different groups of students with different frequency of use. The academic results of these two groups of students were compared and these in turn with those obtained the previous year, in which Kahoot! was not employed; the aim was to measure the extent to which the students' knowledge had developed. The results showed, in all cases, that the use of Kahoot! had led to a significant increase in the overall marks and in the number of students passing the subject. Moreover, some differences were also observed in students' academic performance according to the group. It can be concluded that the use of a gamification tool (Kahoot!) in a university classroom had generally improved students' learning and marks, and that this improvement was more prevalent among students who had achieved a better Kahoot! performance.
\end{abstract}

Keywords: Academic improvement; Gamification; Information and Communication Technologies; Kahoot!; Smartphones; University students. 


\section{Introduction}

Given the strength and interactivity of Information and Communication Technologies (ICT) in all areas of society, the current classroom cannot be conceived without the use of technological tools (Gros \& Contreras, 2006), and in this regard one of the main challenges in the educational field is to determine how ICT can contribute to the objectives and needs of education (Carneiro \& Díaz, 2012). Consequently, it is necessary to determine how the objectives of education can be fostered and assisted by the various tools included in ICT. Several researchers have indicated the improvement in students' motivation when the use of ICT is introduced in their teaching-learning process. One example is the introduction of mobile elements (tablets, smartphones or laptops) in the classroom (Rojas, 2014). Currently, most students attend the university with a very powerful tool in their pockets, the smartphone. It is so widely used that the number of smartphones and/ or tablets on the planet is greater than its population, and Spain is one of the European countries that make most use of them. Mobile devices provide various tools/applications to be used not only within an experimental laboratory, but also in theoretical classes, permitting a complement to the student's training and learning; this means it is better adapted to scientific method (Andújar et al., 2011). However, it is necessary to instruct students in the use of mobile devices (smartphones or tablets) for educational purposes in the classroom, as the correct implementation of this new methodology requires a series of requirements to be met ( $\mathrm{Ng} \&$ Nicholas, 2013).

One clear example of the use of mobile devices in education is gamification, which is understood as the use of mechanisms, aesthetics and thinking in order to attract people, encouraging action, promoting learning and solving problems (Kapp, 2012; RodríguezFernández, 2017). It is obvious that new technologies have contributed to the evolution of gamification, including narrative transmedia. Games do not necessarily have to be played in a static way, but they allow the inclusion of common everyday devices such as the smartphone, thereby opening up new possibilities for attracting those generations accustomed to the use of technologies (Rodríguez-Fernández, 2017). One of the most employed gamification tools is Kahoot!, a free tool that has gained popularity among teachers for its simple use and its ability to establish active work dynamics in the classroom. Kahoot! allows teachers to create surveys, questionnaires and discussions, obtaining feedback from students in real time. In the case of questionnaires, which is the object of our study, the teacher creates the questions and determines the correct answer whilst setting the time in which the student has to respond. The questions are projected in the classroom and the students answer them via their smartphones within the designated time. Each question shows the respective winner and the points are accumulated to offer a final ranking, as if students were in a competition. Thus, Kahoot! questionnaires could be 
seen as an alternative to the traditional way of reviewing a university lecture, whereby instead of the teacher telling students what they should have learnt, this quiz allows them to demonstrate what they have learnt (Young \& Nichols, 2017). There are certain key benefits arising from the approach: i) students see it as an entertaining activity; ii) students have to reflect on what they have learnt in order to answer the questions; iii) teachers can get a sense of how well students have grasped the material from the lessons; iv) students are allowed to obtain immediate formative feedback on their learning without any risk of embarrassment (Hussein, 2015).

The following is a case study, carried out with two groups of students of a third-year theoretical subject in the Chemistry Degree at the University of Valladolid during the present academic year (2017-2018): The gamification tool Kahoot! was applied with different frequency of use. The latter was selected mainly because it is a simple and cheap way to obtain classroom response, in comparison with other tools requiring payment for levels of subscription hiding any premium features, and also as there are no restrictions in terms of the number of questionnaires that can be created or the questions included in each. The academic results of these two groups of students were compared, and then these results were in turn compared with those obtained for the previous year in the same subject (20162017), in which Kahoot! was not used; the aim was to study the potential benefits associated with the use of this tool.

\section{Objectives and Hypotheses}

\subsection{Objectives}

The main goal of this study was to assess the extent to which students' knowledge developed, by comparing their marks after a new pedagogical approach had been applied. This approach was based on ICT and gamification, through the free tool Kahoot!, as an alternative method of teaching and evaluation with respect to traditional methods. The study was performed with two groups of students of a theoretical subject in the Degree in Chemistry at the University of Valladolid. Moreover, certain secondary goals were proposed:

- To ascertain whether there are differences and whether better learning results are obtained when using the Kahoot! tool compared to traditional methods.

- To promote the use of new technologies and digital games in teaching-learning processes via Kahoot!.

- To encourage an entertaining and attractive learning environment that captures the attention and interest of the students.

- To improve the understanding of the Kahoot! tool in order to use it as a means of evaluation in subjects included in the Chemistry Degree. 
- To encourage the motivation and interest among the students to achieve greater active participation and involvement in their own learning process, thereby enhancing their academic performance.

\subsection{Hypothesis}

The study starts from a series of initial hypotheses:

- Kahoot! contributes to improvement in memorising concepts, thus facilitating students' study process.

- Learning results are better thanks to games in the classroom.

- The effectiveness of Kahoot! depends on the frequency of the questionnaires.

\section{Methodology}

The present study approaches gamification as a tool in the university classroom through an empirical-analytical methodology, applying the same type of game (Kahoot! questionnaires), with the same contents, among two groups of students of the same subject. These, who were of similar ages and conditions, had the possibility of previously accessing their notes and attending the theoretical lectures, in which, at the end each lesson, a Kahoot! was proposed on the contents addressed. Both groups of students worked with the same tool (Kahoot!) but the frequency with which they played the games depended on the group. One (Group 1; 42 students) played a Kahoot! questionnaire per lecture, while in the case of the other group (Group 2; 47 students), the game was applied once every two lectures. Each questionnaire consisted of 7 questions and offered four different answers with a single correct option; in all cases, the students had 30 seconds to answer each question. Finally, the teacher gave a short explanation after each question. It should be noted that the participation in the Kahoot! questionnaires was not mandatory, and that the students played the Kahoot questionnaires through their smartphones. To verify if Kahoot! contributed positively to learning outcomes, questions used in the quizzes were included in the partial and final exams of both groups, in this way it was possible to verify if the index of positive answers increased or decreased with respect to those questions that had not been seen in the classroom. Thus, in the partial examination of both groups, 10 test questions were raised, of which 3 had been previously answered through Kahoot!. While the final exam included 5 test questions, of which 2 had been previously answered in the Kahoot! questionnaires. 


\section{Results and Discussion}

\subsection{Students' participation}

As previously mentioned in section 3, student participation in the Kahoot! questionnaires was not mandatory as this was not an official evaluation instrument. Therefore, the number of students that took part in the experiment varied during the semester (see Table 1). As can be seen, the overall number of students that played the different quizzes remained almost constant, although slight variations in both groups were observed in some specific cases.

Table 1. Overall number of students that participated in each of the Kahoot! questionnaires.

\begin{tabular}{cccccccccc}
\hline Lesson & $\mathbf{1}$ & $\mathbf{2}$ & $\mathbf{3}$ & $\mathbf{4}$ & $\mathbf{5}$ & $\mathbf{6}$ & $\mathbf{7}$ & $\mathbf{8}$ & $\mathbf{9}$ \\
\hline Group 1 & 25 & 29 & 31 & 29 & 29 & 29 & 26 & 28 & 27 \\
Group 2 $^{A}$ & $N P$ & 23 & $N P$ & 23 & $N P$ & 22 & $N P$ & 21 & $N P$ \\
\hline
\end{tabular}

NP: not played; ${ }^{A}$ Group 2 played Kahoot! questionaries once each two lessons.

Although the number of participating students was quite similar in all cases, these were not always the same ones: in Groups 1 and 2, these numbered 37 and 28, respectively, figures which are significantly higher than those summarized in Table 1; also as can be seen in Table 2, there was great variability in the number of Kahoot! questionnaires played by each student.

Table 2. Number of students that participated in the Kahoot! questionnaires.

\begin{tabular}{ccccccccccc}
\hline $\begin{array}{c}\mathbf{N}^{\mathbf{0}} \text { of Kahoot! } \\
\text { quizzes }\end{array}$ & $\mathbf{9}^{\mathbf{A}}$ & $\mathbf{8}$ & $\mathbf{7}$ & $\mathbf{6}$ & $\mathbf{5}$ & $\mathbf{4}^{\mathbf{B}}$ & $\mathbf{3}$ & $\mathbf{2}$ & $\mathbf{1}$ & $\mathbf{0}$ \\
\hline Group 1 & 16 & 6 & 3 & 1 & 2 & 2 & 5 & 1 & 1 & 5 \\
Group 2 & $N P$ & $N P$ & $N P$ & $N P$ & $N P$ & 14 & 5 & 6 & 3 & 19
\end{tabular}

NP: not played; ${ }^{\mathbf{A}}$ maximun number of Kahoot! questionaries for Group 1; ${ }^{\mathbf{B}}$ maximun number of Kahoot! questionaries for Group 2;

This could be mainly due to three reasons: i) some of the students had subjects of different courses and therefore did not always attend classes; ii) Kahoot! quizzes were played on the same day that the students had activities relating to other subjects; and iii) students' personal issues. Furthermore, the number of students that participated in the Kahoot! quizzes was significantly higher for Group 1 (37 of 42 students; 88\%) than for Group 2 (28 of 47 students; $60 \%$ ). This difference in the students' participation is difficult to explain, since they were randomly distributed and were always advised of the Kahoot! quizzes one week in advance by the teachers in both groups, in addition to which the activity was 
voluntary. Nevertheless, it is worthy of note that a majority of the students in both groups participated $(\geq 60 \%)$.

\subsection{Comparison of the students' academic performance}

In order to assess the evolution of the students' academic performance after participating in the Kahoot! questionnaires, the results obtained in the partial and final exams were compared with those obtained the previous year. It should be specified that the structures of both exams were quite similar, with the only exception that this year a test-based question was included in the final exam, in order to ascertain the contribution made by Kahoot!. As can be observed in Tables 3 and 4, students' overall marks were significantly higher in both groups, and this correlated directly with the number of students that passed the exam, representing an increase of more than $25 \%$.

In addition, it was found that if only the repeated Kahoot! questions were taken into account (3), the mean mark was higher in Group 1 with respect to the overall mean mark of this group and Group 2. This could be explained by the higher frequency of the Kahoot! quizzes.

Table 3. Comparison of the students'acedemic performance (Group 1) in the partial exam.

\begin{tabular}{cccc}
\hline Academic course & $\begin{array}{c}\text { Mean } \\
\text { mark } \\
\text { (SD) }\end{array}$ & $\begin{array}{c}\text { Mean mark of the } \\
\text { repeated Kahoot! } \\
\text { questions (SD) }\end{array}$ & $\begin{array}{c}\text { \% of students that } \\
\text { passed the exam }\end{array}$ \\
\hline $2016-2017$ & $\begin{array}{c}4.32 \\
(1.75)\end{array}$ & NP & 66 \\
$2017-2018$ (Kahoot!) & 5.98 & 6.46 & 39 \\
& $(1.93)$ & $(2.57)$ & \\
\hline
\end{tabular}

NP: not played; SD: standard deviation.

Table 4. Comparison of the students'acedemic performance (Group 2) in the partial exam.

\begin{tabular}{cccc}
\hline Academic course & $\begin{array}{c}\text { Mean } \\
\text { mark } \\
\text { (SD) }\end{array}$ & $\begin{array}{c}\text { Mean mark of the } \\
\text { repeated Kahoot } \\
\text { questions (SD) }\end{array}$ & $\begin{array}{c}\text { \% of students that } \\
\text { passed the exam }\end{array}$ \\
\hline $2016-2017$ & 4.41 & NP & 68 \\
$2017-2018$ (Kahoot!) & 5.82 & 5.70 & 39 \\
& $(1.96)$ & $(2.42)$ & \\
\hline
\end{tabular}

NP: not played; SD: standard deviation. 
Regarding students' overall academic performance in the final exam, it is worth mentioning that this was similar to that observed in the partial exam (see Tables 5 and 6). The mean marks were higher in both groups in comparison with the previous year as well as the number of students that passed the final exam. However, in the latter case, there was a significant difference between the two groups concerning the number of students that passed the exam (13\%). Moreover, as was the case of the partial exam, a disparity was also observed in the mean marks of the repeated Kahoot! questions. Both findings could be explained by the frequency with which the Kahoot! questionnaires were played.

Table 5. Comparison of the students'acedemic performance (Group 1) in the final exam.

\begin{tabular}{cccc}
\hline Academic course & $\begin{array}{c}\text { Mean } \\
\text { mark } \\
\text { (SD) }\end{array}$ & $\begin{array}{c}\text { Mean mark of the } \\
\text { repeated Kahoot! } \\
\text { questions (SD) }\end{array}$ & $\begin{array}{c}\text { \% of students that } \\
\text { passed the exam }\end{array}$ \\
\hline $2016-2017$ & 4.00 & NP & 45 \\
& $(1.75)$ & & 74 \\
\hline $2017-2018$ (Kahoot!) & 5.01 & 5.70 & \\
& $(1.74)$ & $(2.99)$ & \\
\hline
\end{tabular}

NP: not played; SD: standard deviation.

Table 6. Comparison of the students'acedemic performance (Group 2) in the final exam.

\begin{tabular}{cccc}
\hline Academic course & $\begin{array}{c}\text { Mean } \\
\text { mark } \\
\text { (SD) }\end{array}$ & $\begin{array}{c}\text { Mean mark of the } \\
\text { repeated Kahoot } \\
\text { questions (SD) }\end{array}$ & $\begin{array}{c}\text { \% of students that } \\
\text { passed the exam }\end{array}$ \\
\hline $2016-2017$ & 4.06 & NP & 41 \\
& $(1.93)$ & & 61 \\
$2017-2018$ (Kahoot!) & 5.07 & 5.10 & \\
& $(1.98)$ & $(2.76)$ & \\
\hline
\end{tabular}

NP: not played; SD: standard deviation.

\section{Conclusions}

The introduction of ICTs in the university classroom, and more specifically the use of a simple gamification tool (Kahoot!), has proven to be positive for the students' academic performance in a Chemistry course. This can be seen in the significant improvement of their marks or in the number of students that passed the exam in relation to that of a previous year in which Kahoot! was not applied. Moreover, it has been observed that the frequency of playing Kahoot! quizzes had an influence on the students' marks, as significant differences were observed in the mean marks obtained in the repeated Kahoot! 
questions in both exams, and in the number of students that passed the final exam. This observation could be related with the students' participation in the Kahoot! questionnaires, which was much higher in Group 1. It may, therefore, be concluded that the goals proposed at the start of the study were successfully achieved and that the initial hypotheses were correct. However, given that the results presented here have been obtained from a pilot study, it is necessary to perform more exhaustive research (different courses and subjects), in order to verify the effectiveness of Kahoot! for improving students' academic performance in the Degree of Chemistry.

\section{Acknowledgements}

Authors gratefully acknowledge funding (Universidad de Valladolid, Área de Formación e Innovación Docente; Project $N^{\circ} 12$ ). The authors wish also to thank David Rixham (White Rose English School, Valladolid, Spain) for performing the English revision.

\section{References}

Andújar, J. M., Mejías, A., \& Márquez, M. A. (2011). Augmented reality for the improvement of remote laboratories: an augmented remote laboratory. IEEE Transactions on Education. 54, 492-500.

Carneiro, R., Toscano, J.C., \& Díaz, T. (2009). Los desafíos de las TIC para el cambio educativo. Madrid: Organización de Estados Iberoamericanos para la Educación, la Ciencia y la Cultura, OEI, Servicio de Publicaciones.

Gros, B., \& Contreras, D. (2006). La alfabetización digital y el desarrollo de competencias ciudadanas. Revista Iberoamericana de Educación, 42, 103-126.

Hussein, B. A. (2015). A blended learning approach to teaching Project management: A model for active participation and involvement: Insights from Norway. Education Sciences, 5(2), 104-125.

Kapp, K. M. (2012). The Gamification of Learning and Instruction: Game-Based Methods and Strategies for Training and Education. New York: Pfeiffer.

Ng, W., \& Nicholas, H. (2013). A framework for sustainable mobile learning in schools. British Journal of Educational Technology, 44, 695-715.

Rodríguez-Fernández, L. (2017). Smartphones y aprendizaje: el uso de Kahoot en el aula universitaria. Mediterranean Journal of Communication, 8(1), 181-190.

Rojas, G. C. (2014). Factores que impiden la aplicación de las tecnologías en el aula. Próxima Zona, 20, 108-118.

Young, S., \& Nichols, H. (2017). A reflexive evaluation of technology-enhanced learning. Research in Learning Technology, 25: 1998. 